\title{
Aquisição de Produtos da Agricultura Familiar em Municípios Paranaenses: análise dos produtos comercializados e dos preços praticados ${ }^{1}$
}

\author{
Joseane Carla Schabarum² e Rozane Márcia Triches ${ }^{3}$
}

Resumo: Este estudo verificou a adequação do artigo 14 da lei no 11.947/2009, os tipos de produtos comercializados e os preços pagos por hortifrútis pela alimentação escolar aos agricultores familiares no estado do Paraná. Foi realizada a coleta dos tipos de produtos e os respectivos preços no site do Fundo Nacional de Desenvolvimento da Educação. Para comparação de preços, foram utilizados os dados da Central de Abastecimento de Curitiba (PR). Como resultados, mais da metade dos municípios (51\%) ainda não cumprem a lei, os outros $49 \%$ atingiram $30 \%$ ou mais. Os grupos de frutas e hortaliças demandaram maiores quantidades de recursos. A maioria dos preços pagos é maior que os praticados na Ceasa, podendo sugerir a prática de um valor que permita levar em conta gastos com logística e outros encargos. Porém, ainda existem vários produtos com preços inferiores, alguns deles comercializados com bastante frequência, sugerindo possíveis prejuízos ao agricultor com esses alimentos. Ressalta-se a importância deste mercado para o desenvolvimento rural e, para tanto, os preços pagos aos agricultores familiares devem ser atrativos e justos, sem prejudicar a racionalização do gasto público. Chegar neste equilíbrio é um desafio às Entidades Executoras, mas primordial para o sucesso desta política.

Palavras-chaves: agricultura familiar, alimentação escolar, preços, segurança alimentar e nutricional, políticas públicas.

\begin{abstract}
This study verified the adequacy of the article 14 of Law 11.947/2009, the types of products marketed and prices paid for vegetables for school feeding to family farmers in Paraná state. The types of products and respective prices were collected on the website of the National Fund for Education Development. In order to compare prices, we used data from the Food Supply Center of Curitiba (Paraná). As results, we obtained that more than half of municipalities (51\%) still do not comply with the law, the other $49 \%$ reached $30 \%$ or more. Groups of fruits and vegetables demanded more resources. The prices paid are mostly higher than those practiced at Ceasa, and may suggest the practice of a value that allows taking into account expenses with logistics and other charges.

1. Data de submissão: 31 de julho de 2017. Data de aceite: 26 de fevereiro de 2018.

2. Universidade Federal da Fronteira Sul. Laranjeiras do Sul-PR, Brasil. E-mail: joseschabarum@hotmail.com

3. Universidade Federal da Fronteira Sul. Realeza-PR, Brasil. E-mail: rozane.triches@gmail.com
\end{abstract}


However, there are still several products with lower prices, some of them marketed quite frequently, suggesting possible losses to the farmers with these foods. It is important to emphasize the importance of this market for rural development and, for this reason, the prices paid to family farmers must be attractive and fair, without harming the rationalization of public spending. Reaching this balance is a challenge to the executing entities, but paramount to the success of this policy.

Key-words: family farming, school feeding, prices, food and nutritional security, public policies.

Classificação JEL: JEL: H57

DOI: http://dx.doi.org/10.1590/1234-56781806-94790570103

\section{Introdução}

O PNAE se caracteriza como um programa de abrangência universal dos escolares no nível nacional e de orçamento extremamente vultuoso (THIES et al., 2016). Configura-se, assim, como uma política pública que pode ser utilizada como ferramenta do Estado para alcançar segurança alimentar e nutricional a partir da oferta de alimentos de qualidade para os alunos e também como mercado para a inserção de pequenos agricultores. Conforme defendem Morgan e Sonnino (2008), as aquisições públicas devem ser pautadas na qualidade dos alimentos no médio/longo prazos (best value), levando em consideração seus impactos nos aspectos de saúde, ambiente e sociedade, para além da simples análise de menor preço (value for money), baseado na concorrência, a exemplo do modelo ortodoxo de compras públicas utilizado no Brasil.

A discussão que permeia os mercados institucionais se baseia em oportunidade de comercialização a preço justo, que corresponde a um preço que seja acordado mutuamente com o produtor e as partes envolvidas (LIMA, 2016). Ou seja, o preço justo é o

"valor do produto ou serviço construído a partir do diálogo, da transparência e da efetiva participação de todos os agentes envolvidos na sua composição que resulte em distribuição equânime do ganho na cadeia produtiva" (FRANÇA et al., 2012, p. 5).

Ele não se refere a um preço mais baixo que os do mercado convencional, cobre para além de custos de produção, custos financeiros, ambientais, culturais, sociais e de gênero.

Por sua vez, o conceito de qualidade abordado aqui perpassa os aspectos sanitários e microbiológicos e incorpora aspectos ambientais, de saúde, culturais, sociais e econômicos (TRICHES; SCHNEIDER, 2010). Com efeito, Triches, Gerhardt e Schneider (2013) destacam que, se os problemas de saúde são determinados pelo nosso meio de vida,

"considera-se a alimentação o principal contribuinte, então, pensar a saúde da população é pensar o modelo agroalimentar e, consequentemente, o modelo de desenvolvimento que a sociedade pretende" (p. 110).

Ao pensar sobre o modelo agroalimentar, ressalta-se a preocupação com as consequências do sistema dominante, que foi em grande parte responsável pelos prejuízos à saúde pública, ao meio ambiente e colaborou, em última análise, para o acirramento da desigualdade social. A produção pautada em monoculturas, com vasto uso de agrotóxicos, insumos e aditivos químicos, realizada em larga escala de produtos padronizados e altamente industrializados e dependentes de cadeias de abastecimento cada vez mais complexas, impactou drasticamente na saúde e na segurança e soberania alimentar do País. Dessa forma, outros modelos têm sido buscados que beneficiem a população e o meio ambiente. A agricultura familiar (AF) se apresenta como uma alternativa, já que possui um perfil social, econômico, cultural e ambiental afeito à promoção da segurança alimentar e nutricional, por sua tendência ao fortalecimento das estratégias de auto- 
consumo, diversificação e integração das atividades produtivas e na busca pela inserção em circuitos locais e regionais de comercialização, promovendo o desenvolvimento rural sustentável (PLOEG, 2008; PEREZCASSARINO, 2012).

Dessa forma, programas públicos alimentares, como o Programa Nacional de Alimentação Escolar (PNAE), despontam como potenciais reintegradores desses aspectos, em face das condições de auxiliar no enfrentamento das problemáticas referentes ao consumo, à produção e à comercialização de alimentos. Isto se dá, por um lado, mediante a integração de políticas relacionadas à saúde da população de escolares, e, por outro, mediante a criação de mercados para os agricultores familiares, inclusive com potencial para fomentar práticas de gestão ambiental.

Neste sentido, a partir da lei no 11.947/2009 e de seu artigo 14, o Brasil passa utilizar as compras públicas do PNAE para voluntariamente favorecer este outro modelo agroalimentar centrado no abastecimento a partir de cadeias curtas, via agricultura familiar. Assim, obriga todas as Entidades Executoras (EEx) a utilizarem no mínimo $30 \%$ do recurso do governo federal para a aquisição de produtos da $\mathrm{AF}$.

Desde a criação desta lei, vários estudos (BACCARIN, et al., 2017; FERIGOLO et al., 2017; TEO; TRICHES, 2016; TRICHES et al., 2016) vêm pesquisando como está ocorrendo a implementação deste processo em diversas partes do País, pois o mesmo se caracteriza por ser uma inovação, além de necessitar uma configuração de atores, processos e instituições trabalhando conjuntamente para que o mesmo funcione. No entanto, a maioria dos dados encontrados na literatura se refere a estudos em níveis local ou microrregional, não podendo ser possível realizar uma caracterização do estado em geral, pela grande particularidade de cada região.

Não obstante, é importante destacar que estudos mais abrangentes encontrados até agora sobre a demanda de produtos alimentares da AF para o PNAE no Paraná foram desenvolvidos a partir da análise das chamadas públicas, o que na verdade reflete apenas a intenção de compras, não a efetivação da compra propriamente dita. Da mesma forma, raríssimos são os estudos que avaliaram a questão de preços do PNAE, se esses preços estão de acordo com os do mercado e se podem ser considerados justos ao agricultor.
Portanto, esse estudo teve por objetivo verificar como estas aquisições públicas de produtos da AF para o PNAE no estado do Paraná ocorreram em 2014 (dados mais recentes disponibilizados pelo FNDE). Mais especificamente, identificar a adequação dos municípios paranaenses com relação ao atendimento ao artigo 14 da lei oㅜ 11.947/2009, tipo e quantidade de produtos adquiridos, bem como o montante de valores alocados e, finalmente, analisar se os valores pagos para produtos hortifrútis aos AFs são justos se comparados ao operacionalizados no mercado atacadista.

Dessa forma, este artigo é composto por mais quatro seções além desta introdução. Na sequência, apresenta-se a metodologia utilizada para após explicitar como os municípios pesquisados estão implementando as compras de produtos da $\mathrm{AF}$, os tipos e quantidades de produtos adquiridos. Após isso, o artigo realiza uma análise dos preços pagos aos AFs pelos produtos hortifrútis, seguida pelas considerações finais.

\section{Procedimentos metodológicos}

A presente pesquisa foi de abordagem quantitativa, com análise descritiva de dados secundários. A amostra de municípios do estado do Paraná foi calculada através do índice de correção para população finita, de acordo com Vieira (2010), e resultou em um total de 132 municípios dos 399 existentes. O valor financeiro repassado a cada município em 2014 foi coletado no Sistema de Gestão de Prestação de Contas (Espaço SiGPC - Contas Online), no site do FNDE, e comparado com o destinado a compras da agricultura familiar pela análise das notas fiscais disponíveis no site.

Quanto à adequação dos municípios ao artigo 14 da lei $\mathrm{n}^{\mathrm{o}} 11.947 / 2009$, as prefeituras foram classificadas nos seguintes níveis: não atendimento, atendimento parcial (gasto menor que 30\% com produtos da $\mathrm{AF}$ ), atendimento legal (gasto entre 30 e $40 \%$ com produtos da $\mathrm{AF}$ ), atendimento diferenciado (gasto acima de $40 \%$ com produtos da $\mathrm{AF}$ ).

A partir das notas fiscais que foram coletadas no site do FNDE, foram identificados os tipos de alimentos e preços, sendo todos eles convertidos (quando necessário) para medidas de quilo/litro. Os alimentos foram categorizados em dez grupos: cereais e deriva- 
052 - Aquisição de Produtos da Agricultura Familiar em Municípios Paranaenses: análise dos produtos comercializados e dos preços praticados

dos, açúcares e doces, hortaliças e derivados, frutas e derivados, carnes e derivados, leite e derivados, feijões, tubérculos e derivados, ovos e outros gêneros alimentícios. A partir dessa classificação, foi possível identificar os grupos alimentares adquiridos em maiores quantidades e para quais foi dispendido o maior recurso do governo federal nos municípios do Paraná.

Tendo em vista que cada produto hortifrutigranjeiro, no mesmo mês, apresentava preços diferentes entre as mesorregióes do Paraná, foi calculado o preço médio mensal de cada um deles. Essa formatação para os preços do PNAE se fez necessária para permitir a sua comparação com os preços praticados no mercado, descritos a seguir.

Em relação ao objetivo de comparar os preços dos tipos de gêneros alimentícios da agricultura familiar adquiridos pelas prefeituras municipais do Paraná em relação aos preços praticados na Ceasa PR - foram coletadas nos sites do FNDE (BRASIL, 2016) e da Ceasa e Ceasa PR (BRASIL, 2016; BRASIL, 2016). Isto foi necessário porque o site da Ceasa não contemplava todos os preços mensais dos produtos alimentícios estudados.

Após a consulta aos sites das Ceasas, o estudo considerou 52 produtos hortifrútis, cujo critério de escolha foi a sua disponibilidade de dados. Para os fins desse estudo, foram considerados somente os preços praticados na Ceasa de Curitiba, também para 2014. A Ceasa de Curitiba foi escolhida porque é o principal entreposto de comercialização de hortifrutigranjeiros do Paraná.

Uma vez disponíveis os preços mensais do PNAE e da Ceasa de Curitiba, foi testada a seguinte hipótese nula $\left(\mathrm{H}_{0}\right)$ : os preços praticados pelo PNAE são os mesmos praticados pela Ceasa de Curitiba. A expectativa desse estudo é que a hipótese nula seja rejeitada, de acordo com a ideia de que o preço pago aos AFs deva ser a média de três preços de mercados (preferencialmente locais), que normalmente são varejos. Como hipótese alternativa $\left(\mathrm{H}_{1}\right)$, tem-se que: os preços praticados pelo PNAE são maiores que os praticados pela Ceasa Curitiba para que o mesmo possa ser considerado 'justo'. Esta afirmação baseia-se no artigo 29 da resolução no 26/2013 e seus parágrafos, em que consta que os produtos vendidos ao PNAE pelos AFs devem ser acrescidos de outros encargos, como logística, embalagem, rótulos etc. Para tanto, foi realizada comparação de médias a partir do teste t de Student.

\section{Agricultura familiar e alimentação escolar: efetivação do artigo 14 da lei no 11.947 no estado do Paraná}

O estado do Paraná tem 399 municípios, subdivididos em 10 mesorregióes: centro-ocidental, centro-oriental, centro-sul, metropolitana de Curitiba, noroeste, norte central, norte pioneiro, oeste, sudeste e sudoeste.

Um dado interessante a ser destacado é que praticamente 80\% (317 dos 399) dos municípios do estado têm menos que 20.000 habitantes. Além disso, o Paraná registra 371.051 estabelecimentos agropecuários e, destes, 302.907 são caracterizados como sendo da $\mathrm{AF}$ e, do total da população ocupada (1.117.084) em 2006, $70 \%$ eram vinculados à agricultura familiar, o que dimensiona a importância destes no cenário estadual (Figura 1).

Formando a quarta maior economia do País, o Paraná tem forte perfil agroindustrial, com destaque para produção de grãos (soja, milho, trigo e feijão), óleos vegetais, lacticínios e proteína animal. A atividade industrial também tem importante destaque no estado. O Paraná atende mercados regionais, nacionais e internacionais, principalmente com soja, carnes e automóveis (IPARDES, 2016).

Portanto, a economia rural do Paraná encontra-se fundamentada num ciclo econômico de produção de grãos, cereais e carnes. Não obstante, os dados do censo (2006) mostram que mais de $40 \%$ do valor bruto da produção da agropecuária (VBP-A) no estado vem da AF (PEREIRA; BAZOTTI, 2010).

A análise dos dados de produtos selecionados permite dimensionar a importância da $\mathrm{AF}$, em particular na produção de aves, suínos, mandioca e feijão. Ressalta-se que a produção da AF é voltada primordialmente para o abastecimento interno, sendo que 75,5\% do feijão-preto produzido no Paraná vem da $\mathrm{AF}$, assim como $81 \%$ da mandioca, $43,7 \%$ do milho e $31,2 \%$ da soja. No caso do leite, $67,6 \%$ da produção em 2006 veio da $\mathrm{AF}$, assim como a produção de aves, com $66,5 \%$, e dos suínos, com 62,2\% (PEREIRA; BAZOTTI, 2010).

A partir desta realidade, em que o estado se apresenta com grande número de AFs e com grande produção agropecuária, os resultados deste estudo dão conta que, apesar de a lei 11.947 ser uma obrigatoriedade desde 2009, o que se observa, em se tratando do 
Figura 1. Participação da agricultura familiar e da agricultura não familiar no total dos estabelecimentos agropecuários nas mesorregiões geográficas - Paraná - 2006

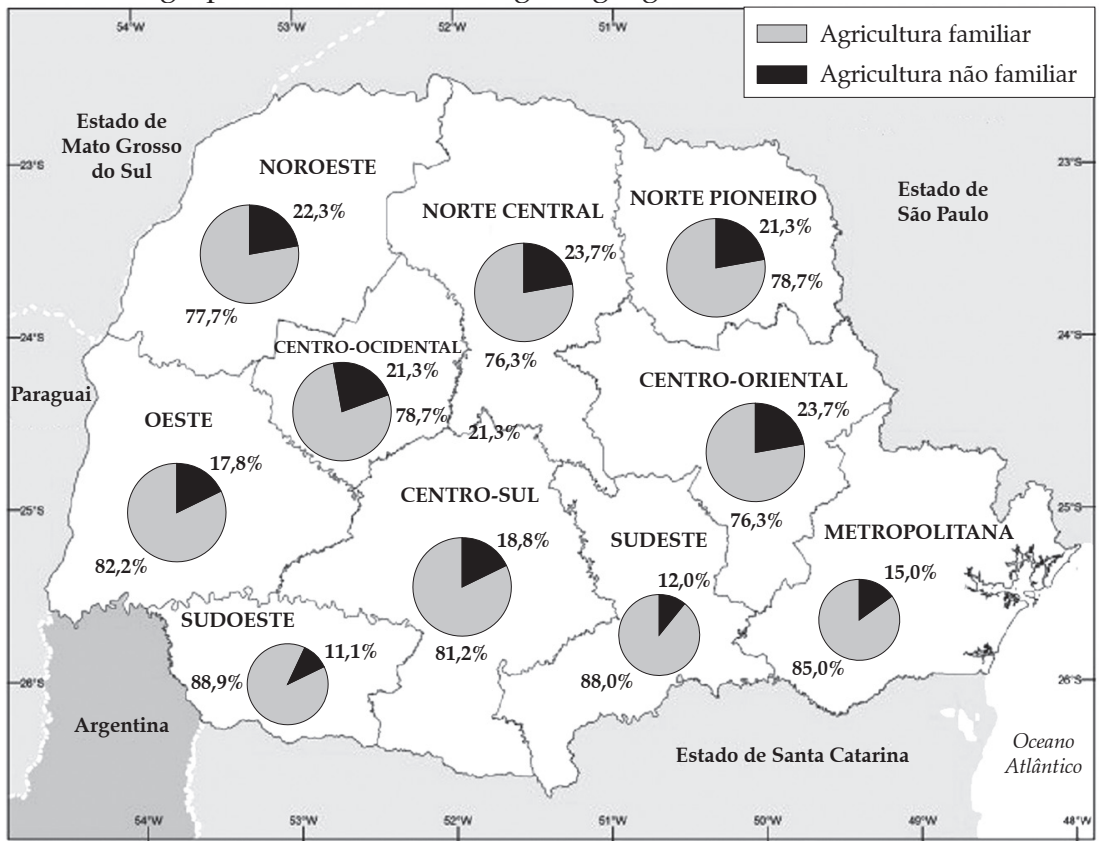

Fonte: Nota técnica Ipardes, 2010.

Paraná, é que mais da metade (51\%) dos municípios analisados ainda não a cumpria em 2014, conforme observa na Figura 2.

Figura 2. Distribuição dos municípios de acordo com o percentual destinado à compra da Agricultura Familiar

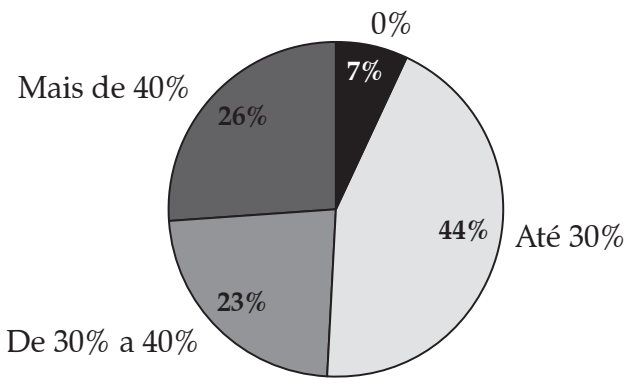

Fonte: Dados da pesquisa, 2017.

Segundo Thies et al. (2016), a região Sul sempre apresentou o maior percentual de aquisição da $\mathrm{AF}$ em comparação às demais regiões do Brasil. Para os autores, o número de prefeituras que apresentaram percentual acima de $45 \%$ de aquisição de alimentos da $\mathrm{AF}$ é extremamente reduzido e, apesar de esse número aumentar significantemente ao passar dos anos, são poucas as prefeituras que justificam essa aquisição pela consciência da importância da compra desse tipo de alimentos, mas sim pela oportunidade de aquisição e pelo cumprimento da lei (THIES et al., 2016, p. 7).

Outros estudos realizados anteriormente, como Saraiva et al. (2013), por exemplo, apontam que, em 2010, primeiro ano da obrigatoriedade de compra da AF, 47,4\% dos municípios do Brasil já adquiriram alimentos da AF. No entanto, os municípios adquiriram, em média, 22,7\% da $\mathrm{AF}$, sendo que a região Sul apresentava maior percentual de aquisição.

Melão (2012), baseado em notícias publicadas pelo MDA, refere que o Paraná, a partir de 2012, foi o primeiro estado a cumprir a legislação federal que determina a aplicação de 30\% dos recursos do PNAE para compra de produtos da $\mathrm{AF}$ em relação às compras das escolas estaduais (o que não foi objeto deste estudo).

Ademais, para Brasil (2015b), o

avanço registrado na aquisição da agricultura familiar para a alimentação escolar já representa uma expressiva e crescente adequação da quase totalidade de entidades executoras 
054 - Aquisição de Produtos da Agricultura Familiar em Municípios Paranaenses: análise dos produtos comercializados e dos preços praticados

no País ao instrumento da chamada pública e à perspectiva da compra pública sustentável (p. 5).

Aprofundando mais na análise dos dados, os resultados da Tabela 1 demonstram que existem especificidades em cada mesorregião quanto às compras de AFs, o que pode ser explicado pelas características relativas à produtividade agrícola, condições econômicas, sociais, de relevo e clima e de desenvolvimento como um todo.

Identifica-se, pelos dados, que as regiões com maior número de municípios atendendo à lei se concentram na região sudoeste $(64 \%)$ seguida pelas regiões oeste $(60 \%)$ e centro-ocidental $(60 \%)$, e as que apresentam menor número são norte pioneiro $(27 \%)$ e sudeste $(33 \%)$, respectivamente. Verifica-se, portanto, uma tendência de as regiões mais interiorizadas do estado atingirem maior sucesso nesta política em relação às mais próximas à capital. Há que se frisar que as regiões oeste e sudoeste lideram em termos do número de ocupados na agricultura familiar. No oeste, são 110 mil ocupados nesta condição e, no sudoeste, mais de 107 mil trabalhadores. Além disso, estas regiões se destacam em número de estabelecimentos da $\mathrm{AF}$. A região sudoeste apresenta o maior percentual de estabelecimentos da agricultura familiar (88.9\%), enquanto o oeste detém o maior número absoluto, 43.752. Por outro lado, os estabelecimentos não familiares estão concentrados nas regiões norte e centro-oriental, o que explicaria em parte estes achados.
No Paraná alguns poucos estudos já vêm sendo realizados sobre o PNAE (MELÃO, 2012; SCHABARUM, 2014; STOLARSKI, 2015; TRICHES; BARBOSA; SILVESTRI, 2016; TRICHES; SCHABARUM; GIOMBELLI, 2016; GREGOLIN, 2016; GREGOLIN et al., 2016) e relatam a efetividade da intenção de compras pelas chamadas públicas dos municípios paranaenses dos gêneros da AF, apontando limitações e potencialidades desse importante programa institucional.

Gregolim et al. (2016), utilizando as chamadas públicas (que se referem apenas à intenção da compra dos alimentos), realizaram um estudo em 2011 na região sudoeste do Paraná e apontaram que 33\% dos municípios não cumpriam a lei (não atingiam 30\% do total, com compras de produtos da AF) e $67 \%$ dos municípios adquiriam pelo menos $30 \%$ de produtos da AF (GREGOLIN et al., 2016). O estudo realizado por Triches, Schabarum e Giombelli (2016), na mesma região, referente ao período de 2013/2014, apontou que $76 \%$ do recurso repassado pelo FNDE seria destinado para a compra de alimentos da AF, segundo as chamadas públicas.

São poucos os estudos que avaliaram a aquisição de alimentos a partir das prestações de contas do FNDE. Stalorski (2015), por exemplo, demonstra em sua análise que, na evolução do PNAE, de 2011 a 2014, além de elevar o valor monetário despendido para alimentação escolar no estado do Paraná, também aumentou o número de municípios que passaram a atender à legislação, à quantidade e à variedade de alimentos adquiridos e do número de fornecedores.

Tabela 1. Número de municípios investigados em cada macrorregião paranaense de acordo com o percentual de compras de produtos da agricultura familiar, 2014

\begin{tabular}{lccccc}
\hline \multicolumn{1}{c}{ Mesorregião } & $\begin{array}{c}\text { Número de } \\
\text { municípios } \\
\text { analisados }\end{array}$ & $\begin{array}{c}\text { Zero N } \\
\mathbf{( \% )}\end{array}$ & $\begin{array}{c}\text { Parcial N } \\
\mathbf{( \% )}\end{array}$ & $\begin{array}{c}\text { Legal N } \\
\mathbf{( \% )}\end{array}$ & $\begin{array}{c}\text { Diferenciado N } \\
(\%)\end{array}$ \\
\hline Noroeste & 20 & $1(5)$ & $10(50)$ & $3(15)$ & $6(30)$ \\
Centro-Ocidental & 10 & - & $4(40)$ & $1(10)$ & $5(50)$ \\
Norte Central & 28 & $5(18)$ & $10(36)$ & $5(28)$ & $5(18)$ \\
Norte Pioneiro & 11 & $3(27)$ & $5(45)$ & $1(9)$ & $2(18)$ \\
Norte Oriental & 4 & - & $2(50)$ & $1(25)$ & $1(25)$ \\
Oeste & 15 & - & $6(40)$ & $4(27)$ & $5(33)$ \\
Sudoeste & 14 & - & $5(36)$ & $5(36)$ & $4(28)$ \\
Centro-Sul & 10 & $1(10)$ & $4(40)$ & $3(30)$ & $2(20)$ \\
Sudeste & 9 & - & $6(67)$ & $3(33)$ & - \\
Metropolitana de Curitiba & 11 & - & $6(54)$ & $5(46)$ & - \\
Total & 132 & $10(7)$ & $58(44)$ & $30(23)$ & $34(26)$ \\
\hline
\end{tabular}

Fonte: Dados da pesquisa (2016). 
Triches, Barbosa e Silvestri (2016) realizaram estudo com 26 municípios paranaenses na vigência 2013/2014 e constaram que, apesar de a demanda de produtos da AF pelas chamadas públicas corresponder a $53,79 \%$, a prestação de contas comprovou que apenas $29,18 \%$ do repasse foi destinado para este fim. Além disso, também encontraram municípios que não atendiam o mínimo da legalidade de aquisição ou ainda que não realizavam nenhuma compra da $\mathrm{AF}$.

Baccarin et al. (2015) indicam que a média do percentual utilizado pelos municípios paranaenses na compra de produtos da AF em 2014 foi de 26,3\%. Já o percentual de compra pela Secretaria Estadual de Educação para as escolas estaduais foi de 51,2\%. No mesmo ano, $60 \%$ dos municípios do Paraná usaram mais de $25 \%$ do recurso enviado pelo FNDE para compra de produtos da AF.

No entanto, para além de verificar o cumprimento da legislação pelos municípios paranaenses, é importante também identificar o que está sendo adquirido e o que isso significa em relação à diversidade e à qualidade dos produtos.

\section{Produtos adquiridos para a alimentação escolar de agricultores familiares nos municípios paranaenses}

O artigo 12 da lei no 11.947 de 2009 considera que a elaboração dos cardápios da alimentação escolar deve ser feita pelo profissional nutricionista, com utilização de gêneros alimentícios básicos, respeitando-se, além dos hábitos alimentares, a cultura e a tradição alimentar da localidade, pautando-se na sustentabilidade e diversificação agrícola da região, na alimentação saudável e adequada e em parâmetros nutricionais adequados aos escolares (BRASIL, 2009).

Observando os alimentos que foram adquiridos, (Figura 3) é possível notar a porcentagem de quilos por grupo de alimento adquiridos em 2014 e o respectivo recurso gasto. Conforme já esperado, os alimentos fornecidos em maiores quantidades pela AF referem-se a alimentos de origem vegetal, frutas, hortaliças, cereais, tubérculos e feijões, representando $83,27 \%$ do volume total das aquisições.

Observa-se que a maior quantidade de alimentos $(41,97 \%)$ adquiridos em 2014 foi do grupo das frutas e derivados, seguido do grupo das hortaliças e derivados, responsável por $26,07 \%$ das aquisições, e dos cereais e derivados, com $11,32 \%$ da quantidade total analisada. Pelo viés nutricional, considerando que os cardápios deverão ser compostos de alimentos básicos, de preferência in natura, e oferecer pelo menos três porções de frutas e hortaliças por semana (200 g/aluno/ semana), os dados do gráfico acima remetem que a aquisição desses alimentos estão conforme orientação da lei.

Essas aquisições vão ao encontro das recomendações do Guia Alimentar para População Brasileira, que visa orientar as escolhas alimentares baseando-se no grau de processamento dos mesmos. O guia destaca a preferência de alimentos o mais natural possível, ou seja, opção pelos in natura, minimamente processados,

Figura 3. Percentual de aquisição por quantidade e valor monetário por grupo de alimentos da Agricultura Familiar para a alimentação escolar em municípios paranaenses, 2014

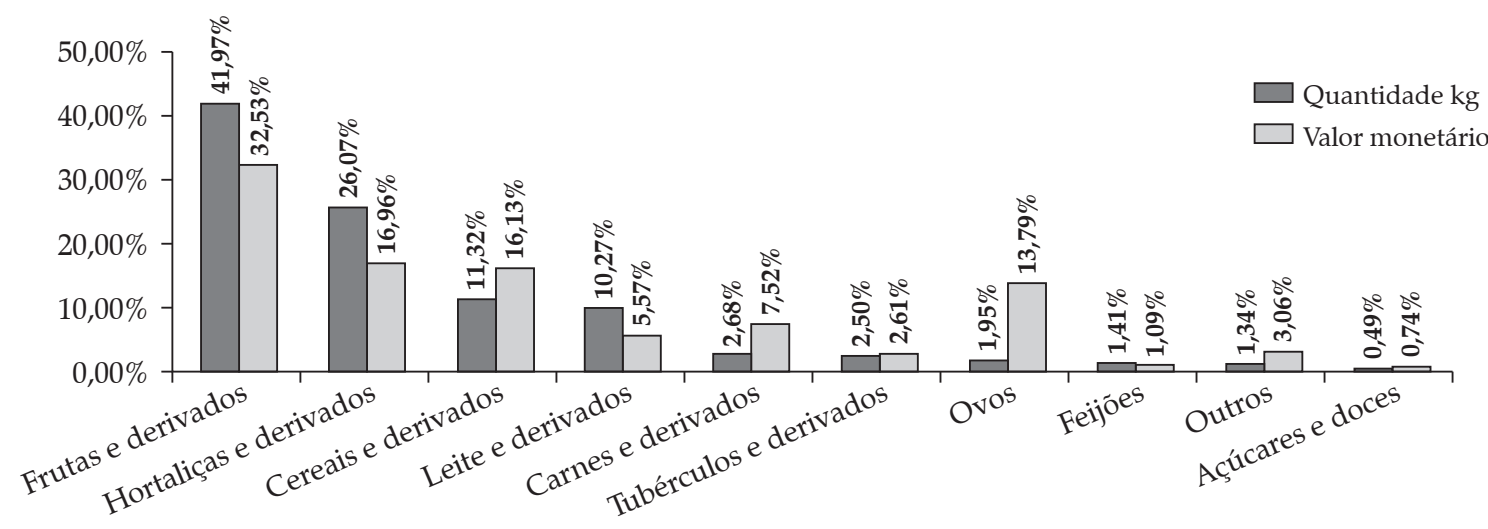

Fonte: Elaborado pelas autoras a partir dos dados do FNDE (2014). 
056 - Aquisição de Produtos da Agricultura Familiar em Municípios Paranaenses: análise dos produtos comercializados e dos preços praticados

e assim por diante, observando cuidados desde sua aquisição, preparo e consumo, sob o mesmo ponto de vista que se refere à lei do PNAE.

Nesse grupo de alimentos in natura podemos citar frutas, hortaliças, raízes, tubérculos e ovos, obtidos sem que sofram qualquer alteração depois de retirados da natureza. No grupo das frutas, adquiridas em maior quantidade em 2014 no estado do Paraná, foram identificados 20 produtos fornecidos na sua forma natural: abacate, abacaxi, banana, laranja, mexerica, limão, mamão, maracujá, melancia, morango, uva, goiaba, pêra, maça, melão, acerola, caqui, manga, kiwi, pêssego. Todas elas estão listadas na produção estadual de frutas conforme Seab/Deral (2017), sendo que as regiões do estado do Paraná desenvolvem a fruticultura, em que a transição climática e os vários tipos de solo do estado são responsáveis por propiciar o cultivo de uma grande diversidade destes produtos.

As frutas são excelentes fontes de fibras, vitaminas e de vários compostos que contribuem para a prevenção de muitas doenças, sendo, portanto, alimentos saudáveis que devem ter sua oferta e consumo constantes (BRASIL, 2014). A análise deste grupo de alimentos remete à conclusão de que os mesmos foram comercializados no PNAE, de acordo com as orientações estabelecidas e respeitando a vocação frutífera local. Outrossim, atualmente, o consumo de frutas, de acordo com Seab/Deral (2017), é menor que o preconizado pela OMS (400g/dia); por conseguinte, a garantia da oferta desses alimentos é um gargalo para o estímulo da própria produção frutífera no estado.

O grupo das hortaliças, de mesma importância nutricional das frutas, aparece como segundo grupo com maior quantidade adquirida dos AFs. Foram identificados 33 itens comercializados na forma in natura: abobrinha, alface, alho, beterraba, almeirão, brócolis, cebola, cenoura, cheiro verde, chicória, chuchu, couve-manteiga, couve-flor, espinafre, pimentão, repolho, rúcula, tomate, vagem, acelga, abóbora, pepino, rabanete, berinjela, cebolinha, agrião, ervilha em vagem, escarola, pimenta fresca, manjericão, abobora, mostarda, quiabo.

A maior parte dos legumes e verduras é produzida o ano inteiro; no entanto, no período de safra os preços ficam menores devido à relação de oferta/ demanda. Esses alimentos, pelas excepcionais propriedades nutricionais e ampla versatilidade culinária (saladas cozidas e in natura, refogados, assados, enso- pados, purês, entre outros), são excelentes alternativas para a promoção de uma alimentação saudável. A presença de antioxidantes justifica inclusive a prevenção contra alguns tipos de câncer, entre outros inúmeros benefícios à saúde (BRASIL, 2014).

A maior aquisição de alimentos de origem vegetal de AFs pode ser explicada pelo fato de serem produtos mais comumente produzidos por eles mesmos (até para autoconsumo). Ademais, itens que antes eram produzidos somente para o autoconsumo passam a representar garantia de comercialização e renda para as famílias rurais fornecedoras ao PNAE, concomitantemente com a melhoria da qualidade alimentar e nutricional nas escolas.

Dados semelhantes foram encontrados nas demandas de alimentos nas chamadas públicas (CPs) analisadas por Melão (2012), Schabarum (2014), Baccarin et al. (2015), Triches, Schabarum e Giombelli (2014), Triches, Barbosa e Silvestri (2016), entre outros. Na análise de Triches, Barbosa e Silvestri (2016), por exemplo, as autoras identificaram no estudo de 26 municípios do Paraná que 37,50\% do total dos produtos das CPs foram de hortaliças, seguido das frutas, com 22,26\%, o que totalizou $59,76 \%$ dos produtos a ser comercializados.

Ribeiro, Ceratti e Broch (2013) destacam que tal situação é prevista por essa atividade já ser estabilizada pelos agricultores familiares e pelo fato de não ter necessidade de maiores adequações aos padrões exigidos de certificação sanitária, como acontece com produtos processados, configurando, assim, a prática mais frequente entre os produtores.

Em relação ao recurso gasto com cada grupo de alimentos, observa-se que o grupo de alimentos de origem animal e com necessidade de maior nível de processamento, como carnes e derivados, ovos, cereais e derivados e outros são os que mais agregam valor se considerado seu volume em quilos/litros.

Chama a atenção a comparação entre as hortaliças e os cereais. Enquanto as hortaliças adquiridas obtiveram uma quantidade em percentual de quilos de mais do dobro dos cereais $(26,06 \%$ e $11,32 \%$, respectivamente), por outro lado, obtiveram praticamente o mesmo percentual de recurso destinado $(11,96 \%$ para hortaliças e $16,13 \%$ para os cereais).

Estes achados apontam para a necessidade de habilitar os AFs dos pontos de vista estrutural e legal, para que possam ter condições de serem também fornecedores destes gêneros alimentícios, fomentando a 
criação de agroindústrias familiares. É importante frisar que as EEx não deixam de comprar estes tipos de alimentos de outros fornecedores, que nada mais são do que atravessadores, atuando no processamento e comercialização dos produtos que são, na maioria das vezes, provenientes da agricultura familiar. Assim, acabam por ficar com o maior percentual do valor pago ao produto.

\section{Preços pagos por hortifrutigranjeiros aos agricultores familiares}

Um marco regulatório importante foi instaurado com o artigo 14 da lei no 11.947/2009, em relação às compras públicas de alimentos para o PNAE, já que abre o precedente de realizar aquisições de AFs sem necessidade de processo licitatório. Neste sentido, prioriza-se este tipo específico de fornecedor, que passa a não concorrer com outros fornecedores potenciais (varejos, atacados, indústria de alimentos). Além de oferecer igualdade de acesso considerando as diferenças entre os diferentes, o processo de dispensa licitatória utilizando a Chamada Pública pré-define os preços a serem pagos aos AFs com base no preço de mercado.

Segundo a resolução no $26 / 2013$, que regulamenta a lei nº 11.947/2009, o preço de aquisição é o preço médio pesquisado por, no mínimo, três mercados em âmbito local, priorizando a feira do produtor da agricultura familiar. Ainda, a mesma institui que a definição dos preços para produtos da AF

"deverá considerar todos os insumos exigidos, tais como despesas com frete, embalagens, encargos e quaisquer outros necessários para o fornecimento do produto. Estas despesas deverão ser acrescidas ao preço médio para definir o preço de aquisição" (BRASIL, 2013; BRASIL, 2015).
Essa discussão se justifica pelo fato de que mesmo que esses mercados sejam apontados como incentivadores do desenvolvimento local, agregando renda aos produtores, o preço também é um item bastante questionado, e que normalmente faz parte, segundo os próprios AFs, dos itens a serem melhorados nas compras institucionais. Conforme relatado por Silva et al. (2016), mesmo que os preços tenham dobrado desde 2012, os agricultores cobram maior valorização dos seus produtos.

O PNAE é constantemente citado como um mercado institucional que, além de caracterizar um mercado seguro, é apontado pela agregação de valor aos produtos comercializados ao Programa. Essa discussão de preços é antiga, e por muitas vezes sugere que os produtos advindos da AF resultem num preço mais barato que os demais mercados. Para suprir as divergências de preços pagos aos agricultores familiares e garantir um preço mais justo, a resolução no 26/2013 deixa claro que todos os custos que incidirem sobre o processo de fornecimento dos alimentos devem ser considerados para elaboração do valor final pago.

Portanto, percebe-se que os preços devem ser definidos não apenas considerando os custos de produção, mas também os custos adicionais. Silva et al. (2016) apontam a mensuração desses custos como fator limitante para a operacionalização do PNAE, tanto pra as EEx quanto para os agricultores (aceitando ou não os preços estabelecidos), sendo que muitas vezes a definição dos preços é realizada de "maneira empírica, sem a utilização de uma metodologia coesa com a realidade dos agricultores e EEx" (p. 3).

Dessa forma, a partir do estudo dos preços pagos aos AFs aos itens adquiridos pelos municípios pesquisados, fez-se a comparação com os preços praticados pelo Ceasa de Curitiba. A Tabela 2 apresenta as médias e as medianas dos preços praticados pelo PNAE e pela Ceasa Curitiba em 2014, além do percentual da diferença entre a média do preço pago pelo PNAE e a média de preço do Ceasa.

Tabela 2. Comparação entre as médias e medianas e diferença percentual entre as médias dos preços pagos aos AFs pelo PNAE nos municípios paranaenses e dos preços praticados no Ceasa de Curitiba para hortifrutigranjeiros em 2014

\begin{tabular}{lccccccc}
\hline \multirow{2}{*}{ Produto } & \multicolumn{2}{c}{ Agricultores } & \multicolumn{2}{c}{ Ceasa } & \multirow{2}{*}{ p-value } & \multirow{2}{*}{ Percentual } \\
\cline { 2 - 5 } & Média & Mediana & Média & Mediana & & & 5,347 \\
Abacate & 3,92 & 3,04 & 2,47 & 2,18 & & 0,70 \\
Abacaxi & 3,46 & 3,39 & 2,18 & 1,80 & & $0,002^{*}$ & 58,72 \\
Abóbora & 1,82 & 1,67 & 1,14 & 1,20 & & $0,000^{*}$ & 59,65
\end{tabular}


058 - Aquisição de Produtos da Agricultura Familiar em Municípios Paranaenses: análise dos produtos comercializados e dos preços praticados

\begin{tabular}{|c|c|c|c|c|c|c|}
\hline \multirow{2}{*}{ Produto } & \multicolumn{2}{|c|}{ Agricultores } & \multicolumn{2}{|c|}{ Ceasa } & \multirow{2}{*}{ p-value } & \multirow{2}{*}{ Percentual } \\
\hline & Média & Mediana & Média & Mediana & & \\
\hline Abobrinha & 1,85 & 1,91 & 1,50 & 1,48 & 0,100 & 23,33 \\
\hline Acerola** & 6,69 & 7,36 & 10,00 & 10,00 & $0,008^{*}$ & $-33,10$ \\
\hline Agrião & 4,77 & 4,80 & 2,90 & 2,50 & $0,001^{*}$ & 64,48 \\
\hline Alface $^{* *}$ & 3,84 & 3,90 & 6,35 & 6,06 & $0,034^{*}$ & $-39,53$ \\
\hline Alho & 11,90 & 10,57 & 4,17 & 1,87 & $0,000^{*}$ & 185,37 \\
\hline Almeirão & 4,60 & 4,55 & 3,76 & 3,51 & $0,045^{*}$ & 22,34 \\
\hline Ameixa vermelha & 4,98 & 5,56 & 4,57 & 4,69 & 0,257 & 8,97 \\
\hline Banana & 1,81 & 1,85 & 1,91 & 1,95 & 0,518 & $-5,24$ \\
\hline Batata & 1,94 & 2,00 & 1,37 & 1,28 & $0,010^{*}$ & 41,61 \\
\hline Batata-doce & 2,16 & 2,16 & 1,52 & 1,56 & $0,034^{*}$ & 42,11 \\
\hline Berinjela & 1,48 & 1,10 & 1,61 & 1,56 & 0,120 & $-8,07$ \\
\hline Beterraba & 1,86 & 1,90 & 1,10 & 1,03 & $0,000^{*}$ & 69,09 \\
\hline Brócolis & 5,91 & 6,09 & 1,43 & 1,38 & $0,000^{*}$ & 313,29 \\
\hline Cebola & 1,66 & 1,60 & 2,95 & 2,69 & $0,000^{*}$ & $-43,73$ \\
\hline Cará** & 1,75 & 1,61 & 1,26 & 1,20 & $0,002^{*}$ & 38,89 \\
\hline Cebolinha & 5,00 & 5,00 & 5,63 & 5,54 & 0,408 & $-11,19$ \\
\hline Cenoura & 1,97 & 1,92 & 1,14 & 1,19 & $0,000^{*}$ & 72,81 \\
\hline Chicória & 4,22 & 3,78 & 2,58 & 2,15 & $0,014^{*}$ & 63,57 \\
\hline Chuchu & 1,74 & 1,80 & 1,03 & 0,73 & $0,003^{*}$ & 68,93 \\
\hline Couve & 4,91 & 4,62 & 2,15 & 2,47 & $0,000^{*}$ & 128,37 \\
\hline Couve-flor & 4,94 & 4,27 & 1,93 & 1,78 & $0,000^{*}$ & 155,96 \\
\hline Inhame & 2,31 & 1,90 & 2,50 & 2,14 & 0,111 & $-7,60$ \\
\hline Kiwi** & 3,59 & 3,72 & 4,62 & 5,00 & $0,009^{*}$ & $-22,29$ \\
\hline Laranja & 1,23 & 1,19 & 0,88 & 0,78 & $0,002^{*}$ & 39,77 \\
\hline Limão & 1,55 & 1,43 & 2,02 & 1,59 & 0,547 & $-23,27$ \\
\hline Maça & 3,30 & 3,26 & 3,38 & 3,25 & 0,187 & $-2,37$ \\
\hline Mamão & 2,96 & 2,94 & 1,73 & 1,72 & $0,000^{*}$ & 71,10 \\
\hline Mandioca & 2,06 & 2,14 & 1,39 & 1,39 & $0,000^{*}$ & 48,20 \\
\hline Mandioquinha & 3,91 & 3,45 & 2,94 & 3,12 & 0,074 & 32,99 \\
\hline Manga & 4,26 & 3,00 & 1,98 & 1,93 & $0,002^{*}$ & 115,15 \\
\hline Maracujá & 5,56 & 4,98 & 3,87 & 3,67 & 0,100 & 43,67 \\
\hline Melancia & 1,09 & 1,05 & 0,87 & 0,84 & $0,003^{*}$ & 25,29 \\
\hline Melão & 2,37 & 2,44 & 2,59 & 2,46 & 0,509 & $-8,49$ \\
\hline Milho verde & 2,86 & 2,83 & 1,44 & 1,60 & $0,000^{*}$ & 98,61 \\
\hline Morango & 9,08 & 9,07 & 8,56 & 8,21 & 0,257 & 6,07 \\
\hline Pepino & 2,00 & 1,83 & 2,08 & 2,27 & 0,518 & $-3,85$ \\
\hline Pera** & 2,66 & 2,88 & 4,14 & 4,06 & $0,002^{*}$ & $-35,75$ \\
\hline Pêssego & 4,15 & 3,85 & 4,39 & 4,50 & 0,308 & $-5,47$ \\
\hline Pimentão & 2,50 & 2,38 & 2,11 & 2,07 & 0,272 & 18,48 \\
\hline Quiabo & 3,22 & 3,00 & 3,42 & 3,71 & 0,219 & $-5,85$ \\
\hline Rabanete & 1,66 & 1,56 & 1,31 & 1,17 & $0,020^{*}$ & 26,72 \\
\hline Repolho & 1,27 & 1,28 & 0,56 & 0,46 & $0,000^{*}$ & 126,79 \\
\hline Rúcula & 4,04 & 3,67 & 3,28 & 3,21 & $0,002^{*}$ & 23,17 \\
\hline Salsinha & 6,37 & 6,34 & 7,05 & 6,17 & 0,249 & $-9,65$ \\
\hline Tangerina** & 1,74 & 1,70 & 2,25 & 2,40 & $0,028^{*}$ & $-22,67$ \\
\hline Tomate & 2,63 & 2,78 & 2,30 & 2,20 & 0,100 & 14,35 \\
\hline Tomate-cereja** & 4,25 & 4,50 & 12,02 & 12,11 & $0,000^{*}$ & $-64,64$ \\
\hline Uva & 3,34 & 2,74 & 4,24 & 4,45 & 0,131 & $-21,23$ \\
\hline Vagem & 2,56 & 2,60 & 3,12 & 3,01 & 0,272 & $-17,95$ \\
\hline
\end{tabular}

* Significativo a $5 \%$.

** Preços estatisticamente menores que os da Ceasa Curitiba.

Fonte: Dados da pesquisa, 2016. 
A partir do teste de significância, observou-se que 31 produtos $(59,62 \%)$ tiveram a hipótese $\mathrm{H}_{0}$ rejeitada, ou seja, apresentam diferenças significativa nos preços pagos e 21 (40,38\%) não apresentaram diferença significativas. Dos 31 produtos em que o preço foi significativamente diferente do pago no atacado, para sete (23\%) deles os preços pagos pelo PNAE são estatisticamente menores que os pagos pela Ceasa Curitiba. Esses produtos são: alface, cará, pêra, tangerina, acerola, kiwi e tomate-cereja. Os outros 24 (77\%) tiveram preços superiores aos de atacado pago aos AFs: rabanete, mandioquinha, cará, laranja, batata, batata-doce, maracujá, mandioca, abacate, abacaxi, abóbora, chicória, agrião, chuchu, beterraba, mamão, cenoura, milho verde, manga, repolho, couve, couve-flor, alho, brócolis.

Ao analisar as diferenças nas médias de preços (mesmo as não significativas entre si), o agricultor estava recebendo menos que os preços praticados pelo Ceasa em 20 itens, com uma variação de $-2,37 \%$ a $-64,64 \%$, média de $-19,60 \%$ se comparado aos preços praticados no Ceasa. Além dos sete alimentos que apresentaram a diferença significativa, outros alimentos que também tiveram um pagamento abaixo do valor do atacado foram: uva, vagem, cebolinha, salsinha, melão, berinjela, inhame, quiabo, pêssego, banana, pepino, maçã.

Ao contrário, em 32 itens, os AFs receberam valores maiores que os praticados no Ceasa, variando de 6,07\% a 313,29\%, média de $67,7 \%$ a mais. Esses alimentos foram, além dos já citados (com diferenças significativas): morango, ameixa vermelha, tomate, pimentão, almeirão, rúcula, abobrinha, melancia.

Esta análise pode indicar algumas reflexões. A primeira delas é a de que há um grande número de itens em que os AFs poderiam ter ganho mais se tivessem vendido seus produtos para o atacado ou para o varejo do que para o PNAE. Pode-se dizer também que o Programa pagou menos aos AFs por estes produtos do que pagaria comprando diretamente no Ceasa. Isso leva a considerar que, para uma boa parcela de produtos, as prefeituras municipais utilizaram o recurso público de forma muito racional. Por outro lado, os AFs podem ter arcado com prejuízos com itens como cebola e tomate-cereja, que apresentaram percentuais de $43,73 \%$ e $64,64 \%$, respectivamente, a menos, se considerar as médias dos valores pagos aos AFs e os praticados no Ceasa em 2014.
A segunda questão a ser pontuada é a de que, na maioria dos itens, os AFs estão conseguindo, em média, um pagamento em torno de $67,70 \%$ a mais por seus produtos se comparado ao preço que a prefeitura pagaria para o atacado. Neste sentido, os custos com logística e outros encargos têm maior chance de estarem embutidos nos preços pagos, sendo positivo para esses fornecedores. Por outro lado, pode estar havendo abusos em alguns itens, como o brócolis e o alho, que tiveram percentual médio pago aos AFs bem acima do operacionalizado pelo Ceasa (313,29\% e 185,37\%, respectivamente). Ao contrário da primeira ponderação, aqui pode ter ocorrido um superfaturamento dos preços pagos aos AFs pelas prefeituras, e que, nesses casos, estas arcaram com o prejuízo.

Uma terceira questão a se considerar é a instabilidade dos preços relativa à sazonalidade, a variações climáticas e à variabilidade entre regiões, já que cada uma delas possui suas especificidades econômicas, de valores de insumos, matérias-primas, mão de obra, vocação agrícola etc., o que leva à certa imprecisão destas análises. Por ter sido feita a partir de uma média de preços anual e apenas de um entreposto da Ceasa, estes valores podem ter alguma variação a depender da época do ano e da macrorregião analisada. Portanto, análises mais apuradas devem ser realizadas para que se possa ter maior clareza sobre o quanto os preços pagos pelas EEx são justos para o $\mathrm{AF}$, mas sem perder de vista a necessária racionalidade no uso do recurso da alimentação escolar para que os alunos não sejam prejudicados.

Além disso, este estudo é pioneiro na pesquisa com preços praticados pelo PNAE para hortifrutigranjeiros no Paraná, já que não foi possível encontrar outros estudos existentes na literatura sobre esse tema. Muito se fala sobre a agregação de valor aos produtos da AF nas vendas públicas; porém, raros são os estudos que trabalham a questão de valores, gastos e de fato avaliam esse ganho aos AFs.

Os agricultores geralmente apontam disparidades com relação aos valores na produção de hortifrutigranjeiros, referindo normalmente como pontos negativos os elevados custos com sementes, insumos, mão de obra, transporte, embalagens etc., e no final da cadeia o baixo preço pago na venda. Tais complicações fazem com que os agricultores levem em conta algumas questões-chaves para a escolha do que vão produzir, como 
060 - Aquisição de Produtos da Agricultura Familiar em Municípios Paranaenses: análise dos produtos comercializados e dos preços praticados

produtos de maior demanda adaptados ao clima da região e ao terreno da propriedade, que exijam menos mão de obra e de fácil produção; que tenham retorno imediato ao investimento e que possam ser produzidos com maior qualidade (COSER et al., 2011).

Isso evidencia, ainda, que a maioria dos agricultores optam pelos mesmos itens a serem produzidos, visando além da melhor condição de produção, um retorno financeiro maior, o que justifica a baixa diversidade frequentemente referida pelos gestores. Essa maior oferta pode, inclusive, refletir no menor preço dos produtos, pois os mesmos são geralmente regulados pela relação de oferta e demanda. E nas épocas específicas os produtos maturam mais rapidamente e simultaneamente, levando ao excesso da oferta (COSER et al., 2011).

No entanto, estes resultados dão pistas de que, em sua maioria, os preços pagos aos AFs por hortifrutigranjeiros parecem atender ao que se considera um preço justo, considerando não só aquele que cubra os custos com produção e logística, mas também que propicie um pagamento digno aos AFs por seu trabalho. Outrossim, nesta argumentação, entram aqui as discussões realizadas por Morgan e Sonnino (2008) sobre o best value, considerando que, ao adquirir estes produtos destes fornecedores, estamos favorecendo a saúde dos alunos, o meio ambiente e a justiça social.

\section{Considerações finais}

A análise aqui desenvolvida possibilitou identificar que ainda existem municípios paranaenses que não conseguem destinar pelo menos $30 \%$ do recurso federal da alimentação escolar para gêneros alimentícios provenientes da agricultura familiar. Nesse sentido, são necessárias pesquisas que busquem identificar os motivos que levam esses municípios a não adquirirem esse percentual mínimo e apontar possíveis caminhos para aquisições da AF.

Conforme resultado já esperado, seja pela maior frequência de produção entre estes, seja pelas dificuldades de adequação às normas e exigências a produções de outros alimentos mais processados, os alimentos de origem vegetal, com destaque para os hortifrutigranjeiros, se efetivam como os mais forneci- dos aos mercados institucionais pelos agricultores. No entanto, no que tange aos preços, esse problema ainda é um dos principais entraves na comercialização, tanto pelo lado da oferta, que considera os preços pagos baixos, tanto pelo lado da demanda, que não quer comprar um produto mais oneroso quando comparado ao atacado e varejo.

Este estudo traz dados que já sinalizam para uma grande variação dos preços, comparando os pagos aos AFs e os praticados pelo atacado. Os preços pagos em sua maioria são maiores aos praticados no Ceasa, podendo sugerir a prática de um valor que permita levar em conta gastos com logística e outros encargos. Porém, ainda existem vários produtos com preços inferiores, alguns deles comercializados com bastante frequência, sugerindo possíveis prejuízos ao agricultor com esses alimentos. Ressalta-se a importância deste mercado para o desenvolvimento rural e, para tanto, os preços pagos aos agricultores familiares devem ser atrativos e justos, sem prejudicar a racionalização do gasto público. Chegar neste equilíbrio é um desafio às Entidades Executoras, mas primordial para o sucesso desta política.

Destaca-se, ainda, a fragilidade desse estudo em comparar todas as mesorregiões com apenas uma Ceasa, o que remete para a importância de outros estudos serem realizados, considerando uma metodologia que dê conta de aprofundar ainda mais esta questão da análise dos preços praticados no PNAE, considerando as especificidades de cada região.

\section{Referências}

BACCARIN et al. Indicadores de Avaliação das Compras da Agricultura Familiar para Alimentação Escolar no Paraná, Santa Catarina e São Paulo. Revista Econ. Sociol. Rural, v. 55, n. 1, jan./mar. 2017.

BRASIL/FNDE/CD/MEC. Lei no 11.947, de 16 de junho de 2009. Dispõe sobre o atendimento da alimentação escolar e do Programa Dinheiro Direto na Escola aos alunos da educação básica; e dá outras providências.

. RESOLUÇÃO № 26, DE 17 DE JUNHO DE 2013. Dispõe sobre o atendimento da alimentação escolar aos alunos da educação básica no âmbito do Programa Nacional de Alimentação Escolar - PNAE. Ministério da Educação. Fundo Nacional de Desenvolvimento da Educação. 2013. 
. Ministério da Educação. Fundo Nacional De Desenvolvimento da Educação. Conselho Deliberativo. Resolução № 4, DE 2 de abril de 2015. Altera a redação dos artigos 25 a 32 da Resolução/CD/FNDE no 26, de 17 de junho de 2013, no âmbito do Programa Nacional de Alimentação Escolar (PNAE), 2015a.

FNDE. Programa Nacional de Alimentação Escolar: Reunião do Comitê Gestor e Grupo Consultivo do art. 14 da Lei no 11.947/09 18 de agosto 2015. Ministério da Educação - MEC Fundo Nacional do Desenvolvimento da Educação - FNDE. Diretoria de Ações Educacionais - DIRAE. Coordenação Geral do Programa de Alimentação Escolar - CGPAE. Divisão de Desenvolvimento da Agricultura Familiar no PNAE DIDAF. Ago. 2015b.

COSER, I. et al. Hortifrutigranjeiros: um estudo da relação consumo/produção da hortifruticultura no município de Erechim/RS. Revista Perspectiva, Erechim. v. 35, n. 130, p. 35-48, jun. 2011.

FERIGOLLO, D. et al. Aquisição de produtos da agricultura familiar para alimentação escolar em municípios do Rio Grande do Sul. Rev. Saúde Pública, v. 51, n. 6, 2017. DOI: http://dx.doi.org/10.1590/ s1518-8787.2017051006648.

FNDE. Fundo Nacional de Desenvolvimento da Educação. Alimentação escolar, 2012. Disponível em: <www.fnde.gov.br>. Acesso em: 15. jun. 2016.

FRANÇA, C. G.; DEL GROSSI, M. E.; MARQUES, V. P. M. A. O Censo Agropecuário 2006 e a Agricultura familiar no Brasil. Disponível em: < http://mineiro13666.com.br/ media/uploads/destaques/arquivos/arq4b1018b266063. pdf $>$. Acesso em: 15 jun. 2017

GREGOLIN, G. C. Alimentação escolar e agricultura familiar: a implementação da Lei 11.947/2009 e seu caráter sustentável no Sudoeste no Paraná. Dissertação (Mestrado) - UNIOESTE - Universidade Estadual do Oeste do Paraná, Centro de Ciências Agrárias, PPGDRS - Programa de Pós-Graduação em Desenvolvimento Rural Sustentável. Marechal Cândido Rondon, 2016.

. et al. Participação da agricultura familiar como fornecedora da alimentação escolar no território sudoeste do Paraná. Revista Nucleus, v. 13, n. 1, abr. 2016.

et al. Participação da agricultura familiar como fornecedora da alimentação escolar no território sudoeste do Paraná. Nucleus, v. 13, n. 1, abr. 2016.

IPARDES. Instituto Paranaense de Desenvolvimento Econômico e Social. Base de Dados do Estado. Disponível em: <http://www.ipardes.gov.br>. Acesso em: 15 jun. 2017.
LIMA, M. A. C. Comércio internacional justo: um modelo econômico alternativo - estruturas, dificuldades e impactos. João Pessoa, 2016.

MELÃO, I. B. Produtos sustentáveis na alimentação escolar: o PNAE no Paraná. Caderno IPARDES - Estudo e Pesquisas, Curitiba-PR, v. 2, n. 2, p. 87-105, jul./dez. 2012. Disponível em: <http://www.ipardes.pr.gov.br/ojs/ index.php/cadernoipardes/article/view/533>. Acesso em: 15 abr. 2015.

MORGAN, K.; SONNINO, R. The school food revolution: public food and the challenge of sustainable development. London: Earthscan, 2008.

PEREIRA, V. V. V. R.; BAZOTTI, A. Ruralidade, agricultura familiar e desenvolvimento. Nota técnica do IPARDES, no 16. Curitiba, 2010.

PEREZ-CASSARINO, J. A construção social de mecanismos alternativos de mercadosno âmbito da Rede Ecovida de Agroecologia. Tese (Doutorado) - Universidade Federal do Paraná. Programa de Pós-Graduação em Meio Ambiente e Desenvolvimento. Curitiba, 2012.

PLOEG, J D. Camponeses e impérios alimentares: lutas por autonomia e sustentabilidade na era da globalização. Porto Alegre: UFRGS Editora, 2008.

RIBEIRO, A. L. P.; CERATTI, S.; BROCH, D. T. Programa Nacional de Alimentação Escolar (PNAE) e a participação da agricultura familiar em municípios do Rio Grande do Sul. Revista Gestão e Desenvolvimento em Contexto - Gedecon, v. 1, n. 1, 2013. Disponível em: <http://revistaeletronica.unicruz.edu.br/index.php/ GEDECON/article/view/282>. Acesso em: 6 nov. 2014.

SARAIVA, E. B. et al. Panorama da compra de alimentos da agricultura familiar para o Programa Nacional de Alimentação Escolar. Revista Ciência E Saúde Coletiva, v 18, n. 4, p. 927-936, 2013.

SCHABARUM, J. C. Demanda para produtos da agricultura familiar e orgânicos/agroecológicos pelo Programa Nacional de Alimentos Escolar na região Sudoeste do Paraná. Trabalho de Conclusão de Curso. Universidade Federal da Fronteira Sul, Curso de Nutrição, Realeza-PR, 2014.

SEAB/DERAL. Estado do Paraná. Secretaria da Agricultura e do Abastecimento. Departamento de Economia Rural. Conjuntura agropecuária safra 2016/17. Mar. 2017.

SILVA, H. A. S.; CAMARA, M. G. G.; TELLES, T. S. Evolução e distribuição espacial da produção de leite no estado do Paraná, Brasil. Acta Scientiarum. Human and Social Sciences Maringá, v. 38, n. 1, p. 37-47, jan./jun. 2016. 
062 - Aquisição de Produtos da Agricultura Familiar em Municípios Paranaenses: análise dos produtos comercializados e dos preços praticados

STOLARSKI, M. C. Construção da política nacional e estadual de alimentação escolar. Cadernos IPARDES, Curitiba-PR, v. 5, n. 1, p. 1-16, jan./jun. 2015.

TEO, C. R. P. A.; TRICHES, R. M. (Orgs.). Alimentação escolar : construindo interfaces entre saúde, educação e desenvolvimento. Chapecó-SC: Argos, 2016.

THIES, V. F. et al. Potencial das compras públicas como mercado para aagricultura familiar - uma análise do PNAE entre 2011-2014 In: 54º Congresso da sociedade Brasileira de Economia, Administração e Sociologia Rural. Maceió-AL, 14 a 17 de agosto de 2016.

TRICHES, R. M.; SCHNEIDER, S. Alimentação escolar e agricultura familiar: reconectando o consumo à produção. Revista Saúde e Sociedade, v. 19, n. 4, p. 933945, 2010.
.; GERHARDT, T. E.; SCHNEIDER, S. Políticas alimentares: interações entre saúde, consumo e produção de alimentos. Revista Interações, Campo Grande, v. 15, n. 1, p. 109-120, 2014. DOI: http://dx.doi. org/10.1590/S1518-70122014000100011.

; SCHABARUM, J. C.; GIOMBELLI, G. P. Aquisição de produtos ecológicos pelo mercado institucionalda alimentação escolar no sudoeste do estado do Paraná. In 53o Congresso da Sociedade Brasileira de Economia, Administração e Sociologia Rural. João Pessoa-PB, 26 a 29 de julho de 2015.

; BARBOSA, L. P.; SILVESTRI, F. Agricultura Familiar e Alimentação Escolar no Estado do Paraná: uma análise das chamadas públicas. Revista Paranaense de Desenvolvimento, Curitiba, v. 37, n. 130, p. 29-43, jan./ jun. 2016.

Todo o conteúdo deste periódico, exceto onde estiver identificado, está licenciado sob uma Licença Creative Commons (cc by 4.0). 